\title{
Evolutionary Metaheuristic Methods Applied to Minimize the THD in Inverters: A Systematic Review
}

\author{
Oscar Sánchez-Vargas ${ }^{1 *}$, Susana Estefany De León-Aldaco ${ }^{1}$, Jesús Aguayo-Alquicira ${ }^{1}$, Adolfo Rafael López-Núñez ${ }^{2}$ \\ ${ }^{1}$ Electronics Department, TecNM / Cenidet, Cuernavaca Morelos 62490, Mexico \\ ${ }^{2}$ Electricity and Power Electronics Laboratory, TecNM/ITESI, Irapuato, Guanajuato 36821, Mexico
}

Corresponding Author Email: m20ce023@cenidet.tecnm.mx

https://doi.org/10.18280/ejee.230308

Received: 7 April 2021

Accepted: 6 May 2021

\section{Keywords:}

differential evolution, evolutive algorithm metaheuristic algorithm, multilevel inverter

\begin{abstract}
In recent research works, metaheuristic methods have been widely used to minimize THD in inverters, these methods provide better computation time and effective results compared to classical methods. This paper presents a systematic analysis with a comprehensive coverage of metaheuristic methods applied to multilevel inverters. The search focused on the characteristics of the inverters used in the articles (topologies, levels, loads and evolutionary method). The aim is to show which are the characteristics of the most used case studies for the application of evolutionary metaheuristic methods. The IEEEXplorer, ScienceDirect, IET Digital Library, Springer and WorldWideScience databases have been used for the review since 2010 . The results of the review show that many researchers use evolutionary algorithms, with Cascaded H-bridge Multilevel Inverter topology, RL loading and 7 levels. This highlights which features of the case studies are the most used and analysed to explore the advantages of using evolutionary metaheuristic methods.
\end{abstract}

\section{INTRODUCTION}

In recent years, several research projects have been carried out on the use of metaheuristic methods to optimize various processes in different areas of science and engineering, to demonstrate that better results can be obtained using these methods and seeking to make the best use of available resources. In short, optimization is to find a better configuration, within a set of variables to achieve the objectives of a problem, with the resources available, without breaking any limits of the process [1]. While metaheuristics are advanced algorithms to solve optimization problems, especially with incomplete or imperfect data [2].

The name or term metaheuristic derives from the Greek suffix "meta" meaning "beyond" or "superior" and the word "heuristic" meaning "to find". Metaheuristic methods can be divided into two main classes: trajectory-based and population-based. Trajectory-based is the term that refers to a search process that is characterized by following a trajectory in the search space. They start with a single initial solution and at each iteration or step, the current solution is replaced by a better solution. The performance of which is usually quite unsatisfactory [3]. They incorporate techniques that allow the algorithm to escape local minima. This implies the need for different criteria to reach a local minimum. Commonly used are the criteria of maximum CPU time, a maximum number of iterations, a solution s of sufficient quality, or reaching the maximum number of iterations without improvement (e.g., SA and TS).

While the population-based one uses a set of solutions also called population of solutions. These try in each iteration to replace the population to obtain a better result, to provide a natural and intrinsic way to explore the search space. However, the final performance depends on how the population is manipulated [3, 4].

Population-based methods have better performance for global optimization [5]. The following Figure 1 gives a classification of the different metaheuristic methods.

This paper shows the results of a systematic review of metaheuristic algorithms used for THD minimization in inverters. The main focus of the review was on reproductive population-based methods, which are mainly subdivided into Evolutionary Algorithms and Swarm Intelligence Algorithms. The objective of the systematic review, covering publications from 2010-2019 (10 years), is to make visible the growing trend in the application of these algorithms for THD minimization in inverters.

It is important to effectively reduce the THD because the presence of harmonics in motors causes heating, causing losses in the core, as well as causing parasitic torques in the axis, causing pulsating torques, as a result of which the motor degrades rapidly $[6,7]$. In electronic equipment, they cause distortion of the voltages at the power supply nodes, causing poor operation in sensitive devices. In conductors they generate an increase in current, causing heating of cables and thermal losses. In capacitors they create parallel resonances in the system and amplification of harmonics causing heating and premature ageing of the capacitors. To find a minimum THD effectively is considered as an optimization problem [8].

The rest of the article is organized as follows: Section 2 contains a brief description, important aspects, and the corresponding equations for THD. Section 3 presents an introduction and characteristics of the metaheuristic methods, as well as diagrams of the DE and GA process. Subsequently, section 4 presents the results of the systematic survey. Finally, the conclusions are presented in section 5 . 


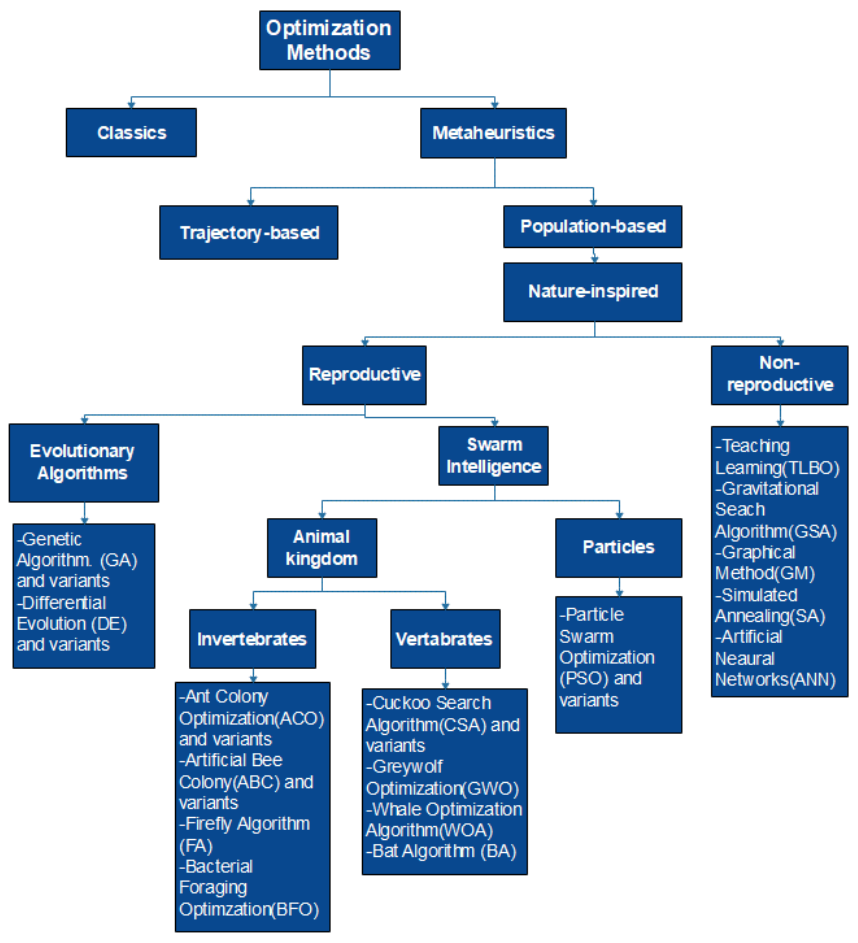

Figure 1. Classification of metaheuristic methods

\section{OPTIMIZATION PROBLEM}

An optimization problem consists of finding the best possible configuration of a set of variables. They fall into two categories: those where the solutions with real variables, and those with discrete variables [1]. In optimization, there are three important aspects, the objective function, decision variables, and constraints. The objective function is the criterion or property to be optimized, it can be expressed in a linear or nonlinear function of several variables; it can be based on weight, cost, volume, efficiency, or a combination of two or more attributes, in this case, it would be the reduction of THD in an inverter [9]. Decision variables or design variables are quantities that in the process are selected by the designer, they cannot be chosen arbitrarily since they must satisfy certain requirements that are specified. While the constraints as the name suggests, are restrictions that must be met in order to develop an acceptable design, they are expressed by linear inequalities $[1,5]$.

In the inverter the stepped waveform of the output voltage is analyzed using the Fourier series which is expressed in the following equation taking into account that it is of quarterwave symmetry:

$$
V_{\text {out }}(\theta)=\sum_{n=1,3,5}^{\infty} b_{n} \sin (n \theta)
$$

where, $n=1,3,5$ are odd harmonics and $b_{n}$ is given by:

$$
b_{n}=\sum_{n=1,3,5}^{2 N-1} \frac{4 V_{d c}}{n \pi}\left(V_{1} \cos \left(n \alpha_{1}\right)+V_{2} \cos \left(n \alpha_{2}\right)+\right.
$$

where:

$n=1,3,5 \ldots 2 \mathrm{~N}-1$ (odd harmonics).

$N=$ number of switching angles per quarter cycle.

$\mathrm{m}=$ number of dc sources.

$a=$ switching angle.
The quality of the voltage waveform at the output is determined by how many harmonics it contains so equation 1 shows the THD formula following the IEEE 519 standard:

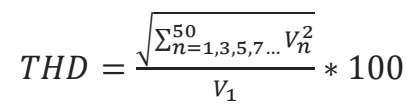

Recalling that the purpose is to minimize the objective function is to find optimal switching angles, having an optimal output voltage. Which can be expressed the objective function as:

$$
\begin{aligned}
& \text { Minimize: } T H D=\frac{\sqrt{\sum_{n=1,3,5,7 \ldots V_{n}^{2}}^{50}}}{V_{1}} * 100 \\
& \text { Subject to: } 0 \leq \alpha_{1} \leq \alpha_{2} \ldots \leq \alpha_{N} \leq \frac{\pi}{2}
\end{aligned}
$$

where, $\mathrm{N}=$ number of switching angles per quarter cycle and $a=$ switching angle.

\section{METAHEURISTIC METHODS}

Metaheuristic methods are advanced search techniques, based on an intelligent procedure to perform an optimization. This process is not as rigorous as other mathematical processes [10]. Metaheuristics are strategies aimed at "guiding" the search process so that the search space is explored efficiently.

Metaheuristic algorithms are usually non-deterministic and therefore provide near-optimal solutions. They include several parameters that must be matched to the problem and may incorporate mechanisms to avoid being trapped in confined areas of the search space. More advanced techniques take advantage of the experience gained from previous searches. In order to guide the current search to a better solution [5].

Compared to classical methods, metaheuristic methods find a solution closer to the optimal one, but with a reduced time, which compensates for the accuracy of the solution with the computational time.

\subsection{Differential evolution}

The Differential Evolution algorithm, created by Rainer Storn and Kenneth Price in 1996, is a metaheuristic method, which conducts a random search in the population of solutions to locate global minima. It perturbs the population generated during the mutation process, while the diversity of the population is controlled by the crossover process [11]. During the selection process, it takes advantage of the survival of the fittest solution. Among the outstanding advantages of the differential evolution algorithm is that it is easy to implement, converges quickly, tends to reach the global optimal solution, and does not tend to remain local solutions [12].

The process of this algorithm consists of the following steps:

1. Initialization: A population of vectors or individuals is randomly generated.

2. Mutation: In this process, genetic characteristics are changed, or rather certain individuals in the population are perturbed. A parent vector is an individual of the current generation, which is called the target vector, the mutant vector obtained after the perturbation is called the donor vector. 
3. Crossover: In this process, the aim is to generate a new generation of individuals or vectors, to have a "better" population. The offspring of the target vector and the donor vector is called the test vector.

4. Selection: In this process evaluates the individuals or test vectors with the target vectors, in other words, they compare parents with sons, in case the target vector turns out to be more effective than the test vector, it stays, otherwise the test vector replaces the target vector, in order to have a new and better generation $[13,14]$.

The processes of mutation, crossover, and selection will be repeated until the result or outcome is satisfactory. Figure 2 shows the ED process:

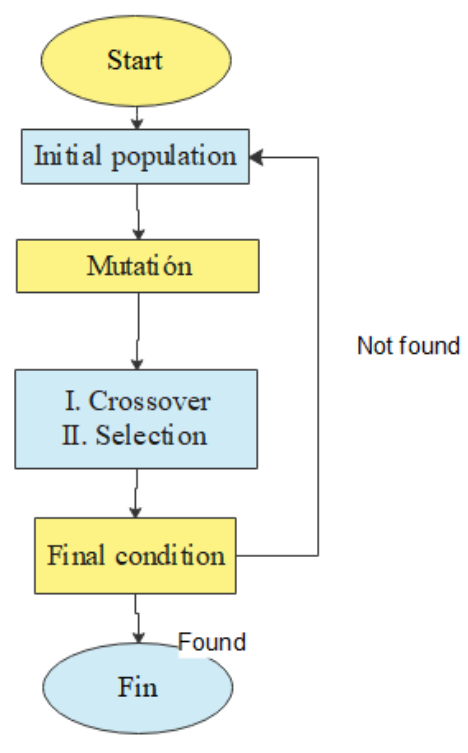

Figure 2. Differential evolution diagram [14]

\subsection{Genetic algorithm}

The Genetic Algorithm (GA) was created by J.H. Holland, in 1970, is a metaheuristic method that is based on the survival of the fittest from Darwin's theory of Natural Selection. The solutions are called "chromosomes" and are submitted to several processes.

It is one of the most widely used methods, it is flexible, it gives optimal solutions in a short time [12].

The GA encodes the parameters of the problem as genes, then randomly generates a set of solutions to the encoded parameters, these are called "initial population". Each individual that is feasible for the solution is considered a chromosome. The number of chromosomes indicates the size of the population. The chains of genes form a chromosome. In the case of large populations, there will be better genetic diversity, in the case of small populations, there will be a fast run time.

1. Initial population: randomly generates a population.

2. Assesses individual fitness: individual fitness is assessed and assigned to each member of the population. The function must be carefully determined, as it has a large effect on the quality of the outcome.

3. Selection: the best adapted "parents" are selected, according to the desired selection strategy. These are the ones that generate the next generation of individuals. For the next generation to be more fit and survive while the less fit ones are eliminated.

4. Crossover: The selected parents are combined to form the new generation of " sons ". The crossover process ensures that each son has the genes of each of his parents, these are exchanged to form a new and improved combination.

5. Mutation: Here some genes are randomly altered from the sons, to have a wide search space, not to remain stagnant, and prevent the solutions from falling into a local minimum.

6. Evaluation of the fitness function: Here the fitness of the children and parents are evaluated, in case an optimal solution is not reached, the process is repeated.

7. Reinsertion: the members of the older generation are replaced by their children if they have better fitness $[15,16]$.

The GA process is best illustrated in Figure 3:

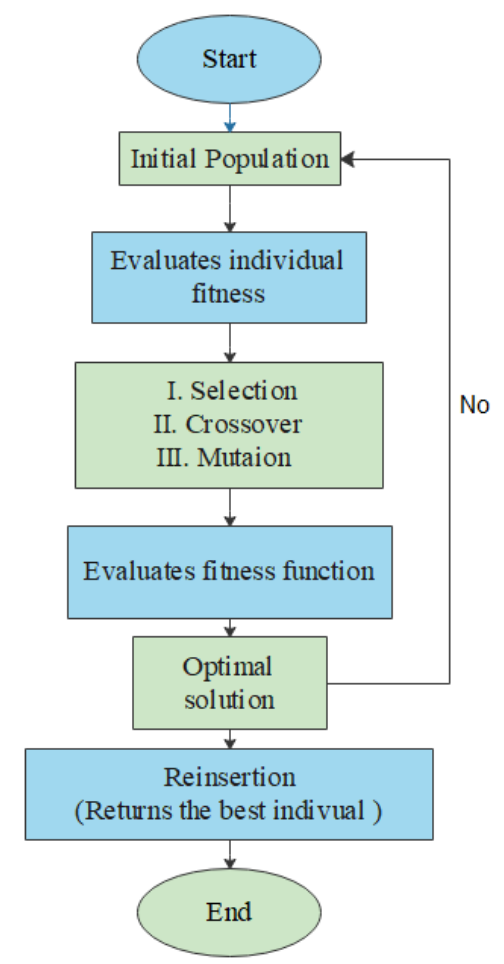

Figure 3. Genetic algorithm diagram [15]

\section{SYSTEMATIC SURVEY RESULTS}

For the literature review analyzed and classified in this article, the IEEExplorer, ScienceDirect, IET Digital Library, Springer, and WorldWideScience databases were consulted.

The search focused on metaheuristic optimization methods applied to basic multilevel inverter topologies (cascaded multilevel, clamped diodes, and flying capacitors), whose objective function was to minimize THD. The database was searched using keywords related to the proposed approach and looking for articles published over 10 years, from 2010 to 2019. A universe of publications of 71 articles was reviewed and classified. Table 1 lists the optimization methodologies used according to their classification. 
Table 1. Classification and optimization methodologies are applied to multilevel inverters

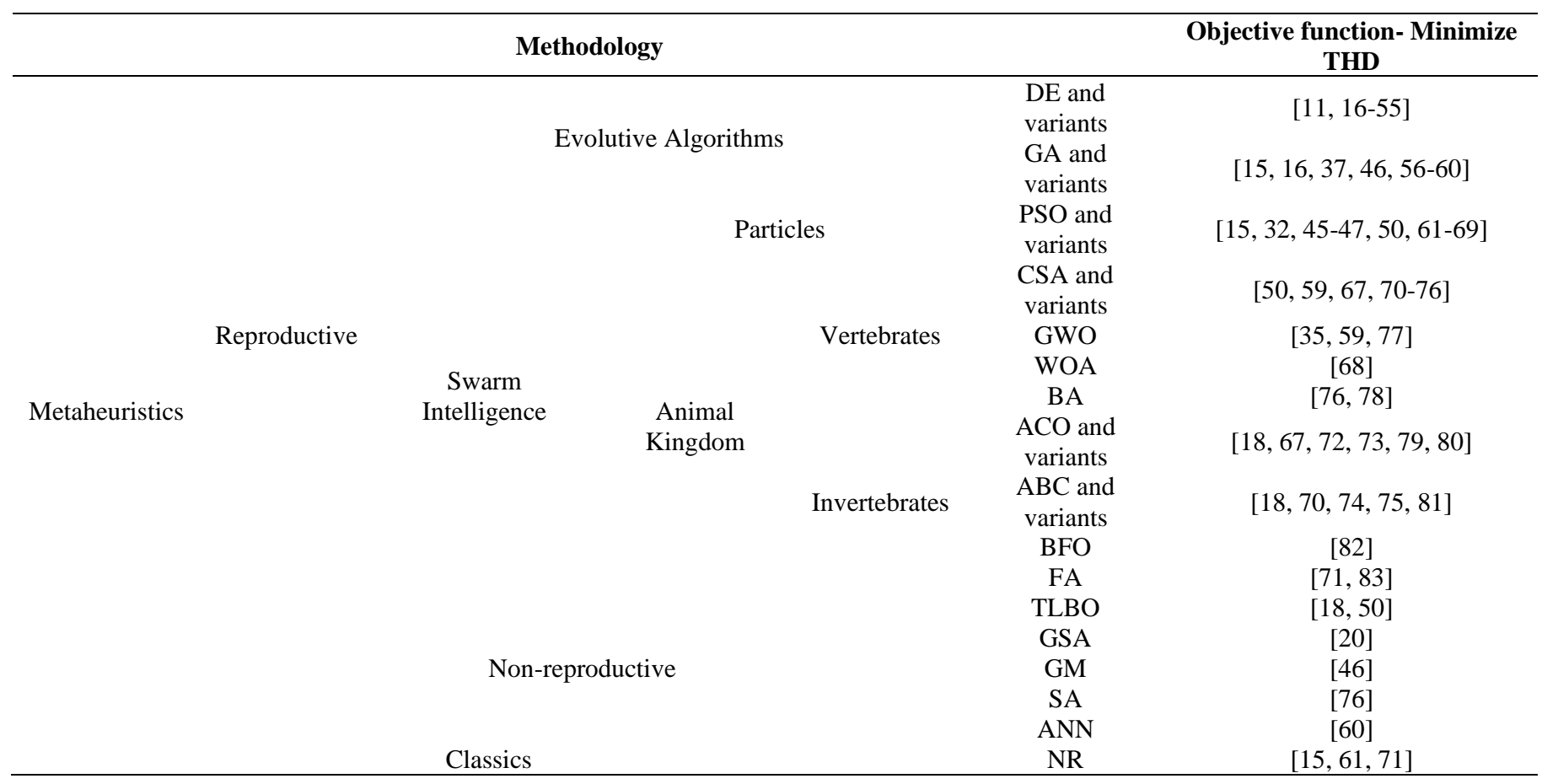

Figure 4 shows a histogram of publications involving optimization procedures in multilevel inverters during the last 10 years and extrapolated for the following years. It can be seen the number of publications has increased significantly in recent years, showing an increasing trend.

In Figure 4, 71 publications were reviewed, 59.15\% of the universe of publications were from conferences, while $40.85 \%$ of publications were from journals.

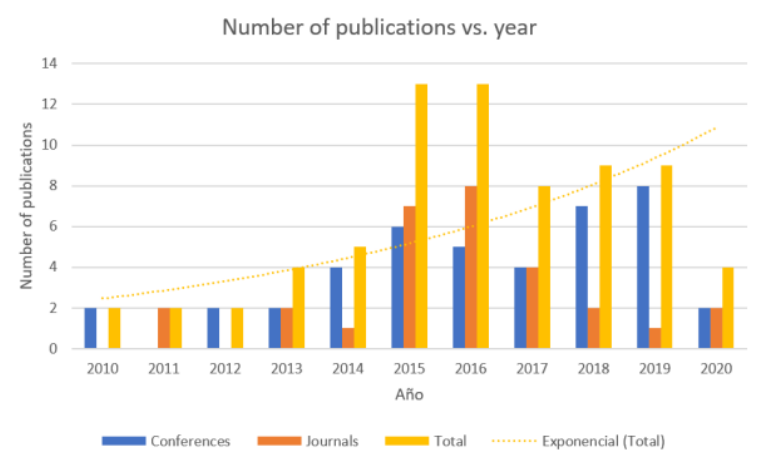

Figure 4. Number of articles using optimization algorithms in multilevel inverters

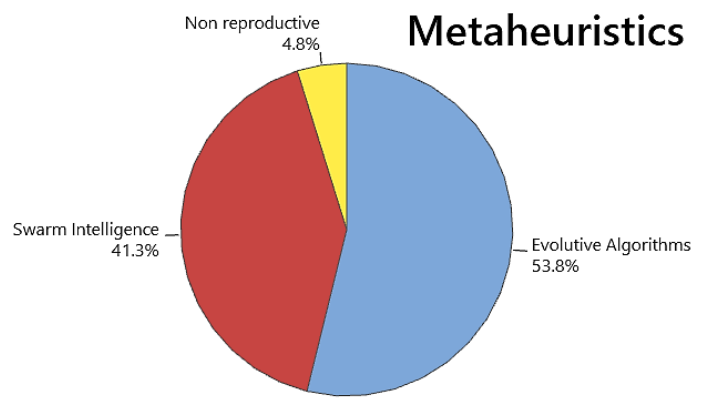

Figure 5. Distribution of metaheuristic methods applied to multilevel inverter optimization
Figure 5 shows the distribution of publications where metaheuristic methods were applied to reduce THD in multilevel inverters.

Figure 6 shows the distribution of publications using evolutive and swarm intelligence algorithms.

\section{Evolutive algorithms}

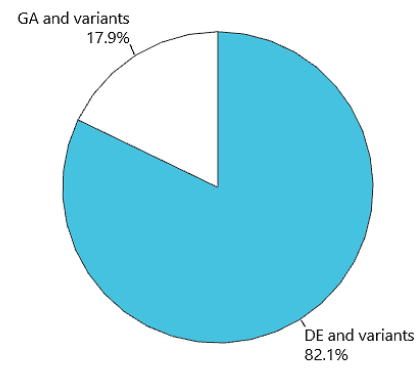

a)

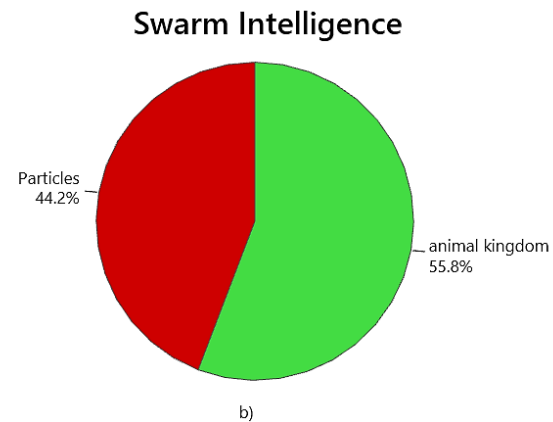

Figure 6. Distribution of publications a) Evolutive algorithms, b) Swarm intelligence

Figure 7 shows the distribution of the animal kingdom classification that invertebrates had $54.2 \%$ of mention in the animal kingdom, while vertebrates had $45.8 \%$. In the case of particles, the majority were PSO and variants.

Figure 8 shows the distribution of levels used in the publications, with the highest frequency of seven levels, followed by five and 11 . 


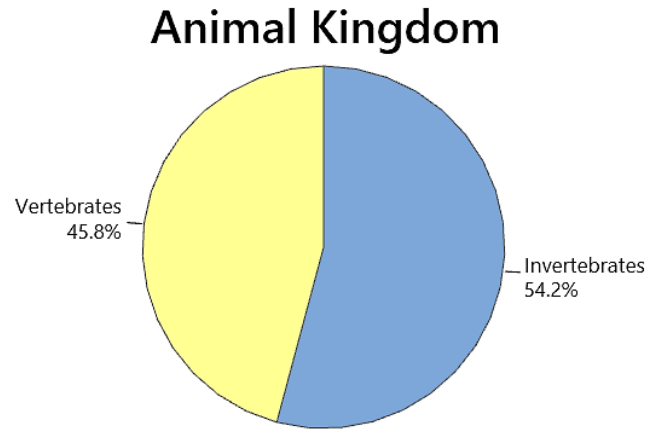

Figure 7. Distribution of publications in the animal kingdom section

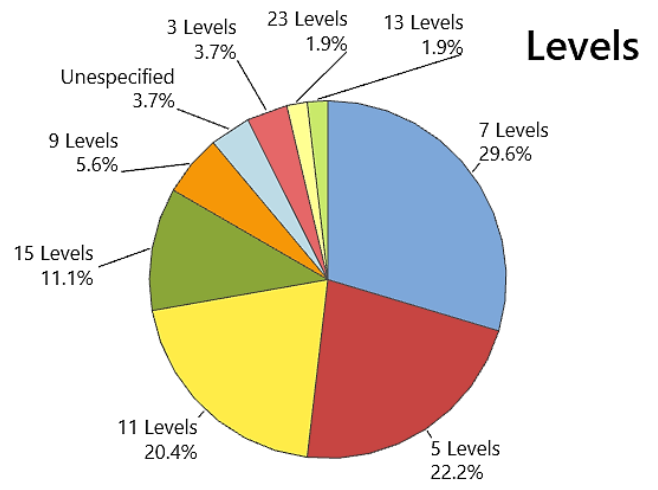

Figure 8. Distribution of publications of the number of levels of an inverter

It is observed that $29.6 \%$ of the publications opt for a multilevel inverter with seven levels.

Another important aspect of the design of a multilevel inverter is its topology. Figure 9 shows the distribution of publications with the different topologies used in these publications.

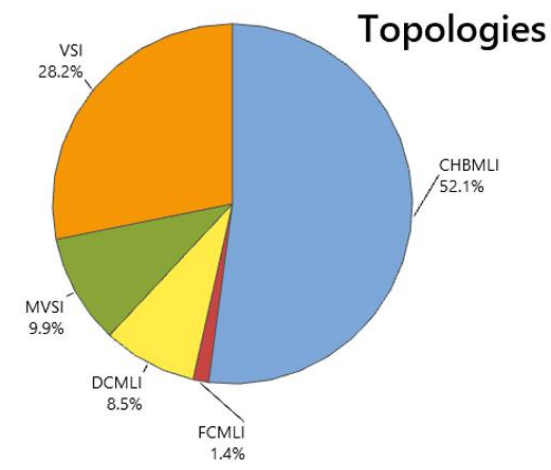

Figure 9. Distribution of publications of the topologies used

The acronyms in Figure 9 are listed:

$>$ CHBMLI: Cascaded H-Bridge Multilevel Inverter.

$>$ FCMLI: Flying Capacitors Multilevel Inverter.

> DCMLI: Diode Clamped Multilevel Inverter.

$>$ MVSI: Multilevel Voltage Source Inverter.

$>$ VSI: Voltage Source Inverter.

Figure 9 shows that in most of the articles analyzed in the review, $52.1 \%$ of the publications used the cascade multilevel topology, observing the clamped diodes in $8.5 \%$ of the universe of publications, while the flying capacitors were $1.4 \%$.
The following figure shows the graph of the universe of publications with the phases of the topologies.

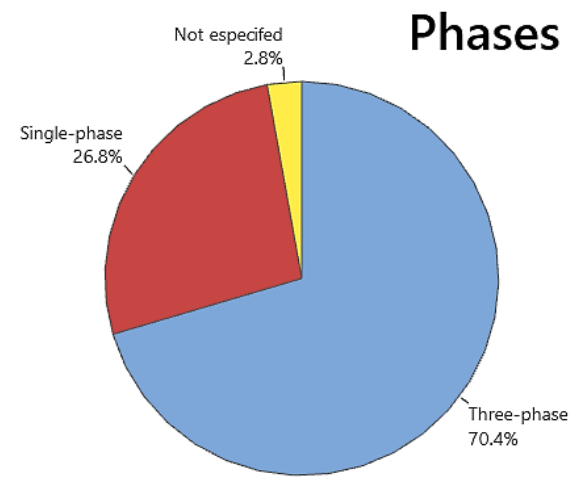

Figure 10. Distribution of publications of the number of phases employed

Figure 10 shows that the majority of the publications used a three-phase inverter with $70.4 \%$, while single-phase inverters were only present in $26.8 \%$ of the publications. Figure 11 below shows the distribution and types of loads used in the publications.

It can be seen in the figure that the RL load has a percentage of $62 \%$, the $\mathrm{R}$ load has a percentage of $26.8 \%$, while the L load has only $4.2 \%$.

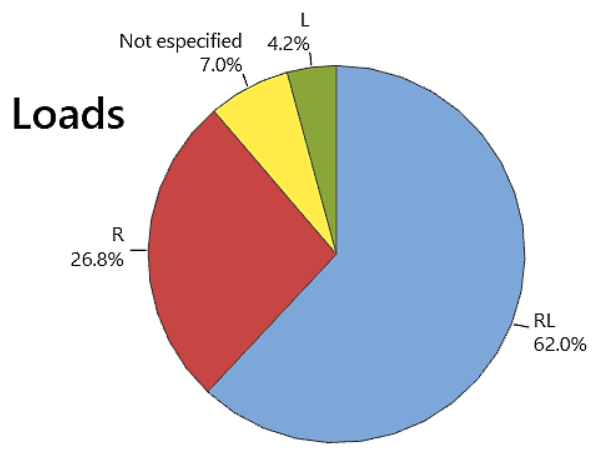

Figure 11. Distribution of publications by type of loads

\section{Off/On-line}

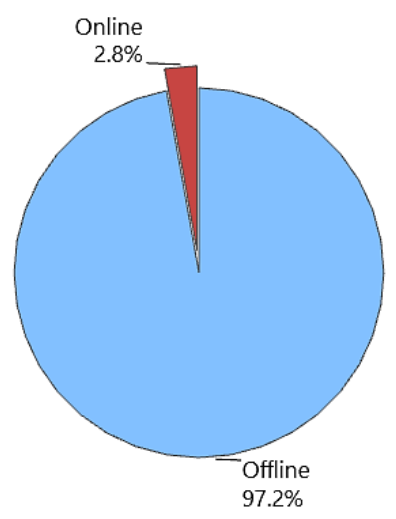

Figure 12. Distribution of Off/On-line configuration publications

A final aspect to consider when a multilevel inverter is whether it performs Off or online, an online optimization allows for restructuring and continuous adaptation while an 
application is running, using the information (maybe variables, or results) live [84]. While offline, data collection and programming are done before and implemented later in the system. The distribution of publications is shown in Figure 12.

The publications that performed Online, were those whose inverters used some hybridization, in addition to using some bio-inspired algorithm used fuzzy logic or some other additional aspect, although the THD reduction was quite effective, the control complexity was increased reasonably.

\section{CONCLUSIONS}

This paper presents a systematic review of the metaheuristic methods used to reduce the harmonic content in an inverter, focusing on multilevel topologies. The mathematical formulation of the objective function was presented.

The metaheuristic algorithms that are of interest for the optimization of the switching angle calculation were briefly introduced, highlighting the advantages over classical methods, and emphasizing the evolutionary methods.

An increasing trend can be observed in the number of scientific articles using metaheuristic methods for THD decrease, as well as new variants of some algorithms. The most used methods are evolutionary algorithms. Within the evolutionary algorithms, the differential evolution algorithm, or variants of this one is having a boom in recent years. Since they have shown quite reliable results and with fewer computer resources.

The articles mostly use seven-level multilevel inverters, although many also use five or eleven levels. Also, the most prominent topology in this article is the cascaded multilevel. Another important aspect is that the articles use more threephase inverters with RL loads. Most of the publications use off-line optimization as it shows satisfactory results, while Online optimization is still rare, these use high computational effort, to ensure that the parameters are available when required.

\section{REFERENCES}

[1] Blum, C., Roli, A. (2003). Metaheuristics in combinatorial optimization: Overview and conceptual comparison. ACM Computing Surveys, 35(3): 268-368. https://doi.org/10.1145/937503.937505

[2] Malik, H. (2020). Metaheuristic and Evolutionary Computation. Springer Nature.

[3] Alba, E. (2005). Parallel Metaheuristics: A New Class of Algorithms (Vol. 47). John Wiley \& Sons.

[4] Herrera, F. (2009). Introducción a los Algoritmos Metaheurísticos. Conferencia de la Asociación Española para Inteligencia Ariticial Universidad de GranadaEspaña, 2009.

[5] De León-Aldaco, S.E., Calleja, H., Alquicira, J.A. (2015). Metaheuristic optimization methods applied to power converters: A review. IEEE Transactions on Power Electronics, 30(12): 6791-6803. https://doi.org/10.1109/TPEL.2015.2397311

[6] Martínez, D.M.M. Analisis Armonico en Sistemas Electricos de Potencia, p. 149, Instituto Tecnológico de Morelia,

[7] Nilsakorn, T., Woranetsuttikul, K., Pinsuntia, K. (2014). Harmonic effect on BLDC motor temperature caused by driving system. In 2014 International Electrical Engineering Congress (iEECON), Chonburi, Thailand), pp. 1-4. https://doi.org/10.1109/iEECON.2014.6925852

[8] Fornieles, F. (2009). Armónicos: Efectos, diagnostico y soluciones. XV Jornadas de Conferencias de Ingeniería Electrónica del Campus de Terrassa, Universitat Politècnica de Catalunya.

[9] Amoiralis, E.I., Tsili, M.A., Paparigas, D.G., Kladas, A.G. (2013). Global transformer design optimization using deterministic and nondeterministic algorithms. IEEE Transactions on Industry Applications, 50(1): 383394. https://doi.org/10.1109/TIA.2013.2288417

[10] Rojas, D.G., Lezama, J.L., Villa, W. (2016). Metaheuristic techniques applied to the optimal reactive power dispatch: A review. IEEE Latin America Transactions, 14(5): 2253-2263. https://doi.org/10.1109/TLA.2016.7530421

[11] Amjad, A.M., Salam, Z., Saif, A.M.A. (2015). Application of differential evolution for cascaded multilevel VSI with harmonics elimination PWM switching. International Journal of Electrical Power \& Energy Systems, 64: 447-456. https://doi.org/10.1016/j.ijepes.2014.07.023

[12] Medina, I.R. (2014). Algoritmos bioinspirados: Una revisión según sus fundamentos biológicos. University of Manchester.

[13] Das, S., Suganthan, P.N. (2010). Differential evolution: A survey of the state-of-the-art. IEEE Transactions on Evolutionary Computation, 15(1): 4-31. https://doi.org/10.1109/TEVC.2010.2059031

[14] Pant, M., Zaheer, H., Garcia-Hernandez, L., Abraham, A. (2020). Differential evolution: a review of more than two decades of research. Engineering Applications of Artificial Intelligence, 103479. https://doi.org/10.1016/j.engappai.2020.103479

[15] Alamri, B., Sallama, A., Darwish, M. (2015). Optimum SHE for cascaded h-bridge multilevel inverters using: NR-GA-PSO, comparative study. 11th IET International Conference on AC and DC Power Transmission, Birmingham, UK, $1-10$. https://doi.org/10.1049/cp.2015.0088

[16] Pawar, S.V., Mrs. Shimi, M.S. (2015). Harmonic elimination in cascade multilevel inverter with non equal dc sources using genetic and differential evolution algorithm. IJISET - International Journal of Innovative Science, Engineering \& Technology, 2(5): 144-150.

[17] Razali, A.M., Kamisman, N., Lazi, J.M., Bahari, N., Abd Halim, W. (2016). Differential evolution technique in solving HEPWM switching angles of three-phase voltage source inverter. 2016 IEEE International Conference on Power and Energy (PECon), Melaka, Malaysia, pp. 489-494. https://doi.org/10.1109/PECON.2016.7951611

[18] Haghdar, K. (2019). Optimal DC source influence on selective harmonic elimination in multilevel inverters using teaching-learning-based optimization. IEEE Transactions on Industrial Electronics, 67(2): 942-949. https://doi.org/10.1109/TIE.2019.2901657

[19] Imarazene, K., Ladjici, A., Berkouk, E.M. (2019). Optimized total harmonic distortion PWM in five level inverter with differential evolution approach. 2019 8th International Conference on Systems and Control (ICSC), Marrakesh, Morocco, pp. 189-193. https://doi.org/10.1109/ICSC47195.2019.8950594 
[20] Naidu, P.A., Singh, V. (2018). Speed control of induction motor and control of multilevel inverter output with optimal PI controller using DE and GSA optimization technique. In 2018 3rd International Conference on Communication and Electronics Systems (ICCES), Coimbatore, India, pp. 920-927. https://doi.org/10.1109/CESYS.2018.8724072

[21] Imarazene, K., Berkouk, E.M., Chekireb, H. (2015). Optimized total harmonics distortion PWM and multicarries PWM: Comparison. 2015 IEEE 5th International Conference on Power Engineering, Energy and Electrical Drives (POWERENG), Riga, Latvia: 337-341. https://doi.org/10.1109/PowerEng.2015.7266340

[22] Biswas, P.P., Awad, N.H., Suganthan, P.N., Ali, M.Z., Amaratunga, G.A. (2017). Minimizing THD of multilevel inverters with optimal values of DC voltages and switching angles using LSHADE-EpSin algorithm. 2017 IEEE Congress on Evolutionary Computation (CEC), San Sebastian, Spain, pp. 77-82. https://doi.org/10.1109/CEC.2017.7969298

[23] Salam, Z., Majed, A., Amjad, A.M. (2015). Design and implementation of 15-level cascaded multi-level voltage source inverter with harmonics elimination pulse-width modulation using differential evolution method. IET Power Electronics, 8(9): 1740-1748. https://doi.org/10.1049/iet-pel.2014.0482

[24] Majed, A., Salam, Z., Amjad, A.M. (2017). Harmonics elimination PWM based direct control for 23-leve multilevel distribution STATCOM using differential evolution algorithm. Electric Power Systems Research, 152: 48-60. https://doi.org/10.1016/j.epsr.2017.06.022

[25] Rashid, M.I.M., Hiendro, A., Anwari, M. (2012). Optimal HE-PWM inverter switching patterns using differential evolution algorithm. IEEE International Conference on Power and Energy (PECon), Kota Kinabalu Sabah, Malaysia, pp. 32-37. https://doi.org/10.1109/PECon.2012.6450232

[26] Salam, Z., Bahari, N. (2010). Selective harmonics elimination PWM (SHEPWM) using differential evolution approach. 2010 Joint International Conference on Power Electronics, Drives and Energy Systems \& Power, New Delhi, India, pp. 1-5. https://doi.org/10.1109/PEDES.2010.5712375

[27] Hang, D., Dutta, R. (2014). Application of partial directpole-placement and differential evolution algorithm to optimize controller and LCL filter design for grid-tied inverter. Australasian Universities Power Engineering Conference, AUPEC 2014, Curtin University, Perth, Australia, pp.

$1-6$. https://doi.org/10.1109/AUPEC.2014.6966518

[28] Salam, Z., Amjad, A.M., Majed, A. (2013). Using differential evolution to solve the harmonic elimination pulse width modulation for five level cascaded multilevel voltage source inverter. 2013 1st International Conference on Artificial Intelligence, Modelling and Simulation, Kota Kinabalu, Malaysia, pp. 43-48. https://doi.org/10.1109/aims.2013.15

[29] Roşu, Ş.G., Rădoi, C., Florescu, A., Guglielmi, P., Pastorelli, M. (2012). The analysis of the solutions for harmonic elimination PWM bipolar waveform with a specialized differential evolution algorithm. 2012 13th International Conference on Optimization of Electrical and Electronic Equipment (OPTIM), pp. 814-821. https://doi.org/10.1109/OPTIM.2012.6231900
[30] Prabhu, M., Rajendran, S., Kohila, J., Kannan, S. (2014). Implementation of SHE in solar energy conversion system. 2014 IEEE International Conference on Advanced Communications, Control and Computing Technologies, Ramanathapuram, India, pp. 270-275. https://doi.org/10.1109/ICACCCT.2014.7019444

[31] Ketabi, A. (2015). Photovoltaic single-stage grid tied inverter with one-cycle control. The 6th Power Electronics, Drive Systems \& Technologies Conference (PEDSTC2015), Tehran, Iran, pp. 257-262. https://doi.org/10.1109/PEDSTC.2015.7093284

[32] Dong, L., Wang, H., Zeng, G.Q., Zhang, Z.J., Wu, L., Xiong, R., Dai, Y.X. (2018). Optimal droop control of distributed inverters in a microgrid under autonomous mode based on differenial evolution. 2018 Chinese Automation Congress (CAC), Xi'an, China, pp. 36843689. https://doi.org/10.1109/CAC.2018.8623493

[33] Wu, J., Bie, L., Jin, N., Guo, L., Zhang, J., Tao, J., Snášel, V. (2020). Dual-frequency output of wireless power transfer system with single inverter using improved differential evolution algorithm. Energies, 13(9): 2209. https://doi.org/10.3390/en13092209

[34] Chabni, F., Taleb, R., Helaimi, M.H. (2016). Differential evolution based SHEPWM for seven-level inverter with non-equal DC sources. International Journal of Advanced Computer Science and Applications, 7(9): 304-311. https://doi.org/10.14569/IJACSA.2016.070943

[35] Stonier, A.A., Chinnaraj, G., Kannan, R., Mani, G. (2020). Investigation and validation of an eleven level symmetric modular multilevel inverter using grey wolf optimization and differential evolution control algorithm for solar PV applications. Circuit World.

[36] Qian, S., Ye, Y., Liu, Y., Xu, G. (2018). An improved binary differential evolution algorithm for optimizing PWM control laws of power inverters. Optimization and Engineering, 19(2): 271-296. https://doi.org/10.1007/s11081-017-9354-5

[37] Sudha Letha, S., Thakur, T., Kumar, J. (2015). Harmonic elimination in a solar powered cascaded multilevel inverter using genetic algorithm and differential evolution optimization techniques. ASME International Mechanical Engineering Congress and Exposition, 57441: V06BT07A048. https://doi.org/10.1115/imece2015-51477

[38] Jamuna, P., Rajan, C.C.A. (2013). A heuristic method: Differential evolution for harmonic reduction in multilevel inverter system. International Journal of Computer and Electrical Engineering, 5(5): 482-486. https://doi.org/10.7763/ijcee.2013.V5.758

[39] Mohapatra, G., Nayak, M.R. (2018). Switching angle and power loss calculation for THD minimization in CHBmultilevel inverter using DEA. Information and Decision Sciences, pp. 491-502. https://doi.org/10.1007/978-98110-7563-6_51

[40] Chabni, F., Taleb, R., Mellakhi, A. (2016). Elimination of harmonics in modified 5-level CHB inverter using DE algorithm. Mediterranean Journal of Modeling and Simulation.

[41] Vijayakumar, R., Devalalitha, C., Nachiappan, A., Mazhuvendhi, R. (2014). Selective harmonic elimination PWM method using two level inverter by differential evolution optimization technique. 2014 International Conference on Science Engineering and Management Research (ICSEMR) Chennai, India, pp. 1-6. 
https://doi.org/10.1109/ICSEMR.2014.7043551

[42] Sureshkumar, L.V., Salma, U. (2019). Differential evaluation base gain tune of proportional-integralderivative controller for mli base-integrated wind energy system with multi-winding transformer. Soft Computing in Data Analytics, pp. 493-505. https://doi.org/10.1007/978-981-13-0514-6_49.

[43] Bahari, N., Salam, Z. (2010). Application of differential evolution to determine the hepwm angles of a three phase voltage source inverter. IECON 2010-36th Annual Conference on IEEE Industrial Electronics Society, Glendale, AZ, USA, pp. 2683-2688. https://doi.org/10.1109/IECON.2010.5675130

[44] Yu, Y., Zhang, P., Song, Z., Chai, F. (2018). Composite differential evolution algorithm for SHM with low carrier ratio. IET Power Electronics, 11(6): 1101-1109. https://doi.org/10.1049/iet-pel.2017.0588.

[45] Srinivas, L.R., Ram, B.M. (2018). Voltage and frequency control of distribution generation unit in an island mode microgrid using differential evolution. 2018 Second International Conference on Intelligent Computing and Control Systems (ICICCS), Madurai, India, pp. 772-778. https://doi.org/10.1109/ICCONS.2018.8663187

[46] Chabni, F., Taleb, R., Cimoroni, M.G., Buccella, C. (2018). Selective harmonic elimination procedure for uniform step asymmetrical 7-level CHB inverter. 2018 5th International Symposium on Environment-Friendly Energies and Applications (EFEA), Rome, Italy, pp. 1-6. https://doi.org/10.1109/EFEA.2018.8617081

[47] Mallick, R.K., Sinha, S., Mohanty, S., Kumar, S. (2016). Design of optimal controller for DSTATCOM using differential evolution technique. In 2016 International Conference on Electrical, Electronics, and Optimization Techniques (Iceeot), Chennai, India, pp. 1432-1437. https://doi.org/10.1109/ICEEOT.2016.7754920

[48] Zhao, G., Huang, X.L. (2013). Application of de algorithm over control of grid-connected PV inverter. Applied Mechanics and Materials, 380: 664-667.

[49] Imarazene, K., Berkouk, E.M., Chekireb, H. (2013). Selective harmonics elimination: PWM method versus optimized total harmonic distortion. In 4th International Conference on Power Engineering, Energy and Electrical Drives, Istanbul, Turkey, pp. 295-298. https://doi.org/10.1109/PowerEng.2013.6635622

[50] Massrur, H.R., Niknam, T., Mardaneh, M., Rajaei, A.H. (2016). Harmonic elimination in multilevel inverters under unbalanced voltages and switching deviation using a new stochastic strategy. IEEE Transactions on Industrial Informatics, 12(2): 716-725. https://doi.org/10.1109/tii.2016.2529589

[51] Hiendro, A. (2011). Multiple switching patterns for SHEPWM inverters using differential evolution algorithms. International Journal of Power Electronics and Drive Systems, 1(2): 94-103. https://doi.org/10.11591/ijpeds.v1i2.101

[52] Razali, A.M., Kamisman, N., Lazi, J.M., Bahari, N. (2016). Differential evolution technique of HEPWM for three-phase voltage source inverter. ARPN Journal of Engineering and Applied Sciences, 11(14): 8958-8964. https://doi.org/10.1109/PECON.2016.7951611

[53] Majed, A., Salam, Z., Amjad, A.M. (2014). HEPWM implementation for fifteen level cascaded inverter using field programmable gate array. 2014 IEEE Conference on Energy Conversion (CENCON), Johor Bahru,
Malaysia,

pp.

$331-335$.

https://doi.org/10.1109/CENCON.2014.6967525

[54] Darvishi, A., Alimardani, A., Hosseinian, S.H. (2011). Fuzzy multi-objective technique integrated with differential evolution method to optimise power factor and total harmonic distortion. IET Generation, Transmission \& Distribution, 5(9): 921-929. https://doi.org/10.1049/iet-gtd.2010.0712

[55] Mohapatra, G. (2018). Current control of a PV integrated CHB-multilevel inverter using PR controller. In 2018 Technologies for Smart-City Energy Security and Power (ICSESP), Bhubaneswar, India, pp. https://doi.org/10.1109/ICSESP.2018.8376734

[56] Arani, A.K., Ghasemi, A., Karami, H., Akhbari, M., Gharehpetian, G.B. (2019). Optimal switching algorithm for different topologies of 15-level inverter using genetic algorithm. In 2019 5th Conference on Knowledge Based Engineering and Innovation (KBEI), Tehran, Iran, pp. 352-358. https://doi.org/10.1109/KBEI.2019.8734966

[57] Chatterjee, A., Rastogi, A., Rastogi, R., Saini, A., Sahoo, S.K. (2017). Selective harmonic elimination of cascaded H-bridge multilevel inverter using genetic algorithm. In 2017 Innovations in Power and Advanced Computing Technologies (i-PACT), Vellore, India, pp. 1-4. https://doi.org/10.1109/IPACT.2017.8245005

[58] Deniz, E., Aydogmus, O., Aydogmus, Z. (2016). Implementation of ANN-based selective harmonic elimination PWM using hybrid genetic algorithm-based optimization. Measurement, 85: 32-42. https://doi.org/10.1016/j.measurement.2016.02.012

[59] Nalcaci, G., Ermis, M. (2019). Effect of grey wolf optimization on thd of 3-phase voltage source inverter with selective harmonic elimination base. 4th International Conference on Power Electronics and their Applications (ICPEA), Elazig, Turkey, pp. 25-27. https://doi.org/10.1109/ICPEA1.2019.8911198

[60] Deniz, E., Aydogmus, O., Aydogmus, Z. (2015). GAbased optimization and ANN-based SHEPWM generation for two-level inverter. IEEE International Conference on Industrial Technology (ICIT), Seville, Spain, pp. https://doi.org/10.1109/ICIT.2015.7125186

[61] Letha, S.S., Thakur, T., Kumar, J. (2016). Harmonic elimination of a photo-voltaic based cascaded H-bridge multilevel inverter using PSO (particle swarm optimization) for induction motor drive. Energy, 107: 335-346. https://doi.org/10.1016/j.energy.2016.04.033

[62] Memon, M.A., Mekhilef, S., Mubin, M. (2018). Selective harmonic elimination in multilevel inverter using hybrid APSO algorithm. IET Power Electronics, 11(10): $1673-1680 . \quad$ https://doi.org/10.1049/ietpel.2017.0486

[63] Adeyemo, I.A., Okediran, O.O., Oyeleye, C.A. (2015). Particle swarm optimization approach to harmonic reduction in voltage source multilevel inverter. International Journal of Soft Computing and Engineering, 5(5): 1-5.

[64] Omar, R., Rasheed, M., Sulaiman, M. (2019). A single phase of modified multilevel inverter using particle swarm optimization (PSO) algorithm. 2019 IEEE International Conference on Automatic Control and Intelligent Systems (I2CACIS), Selangor, Malaysia, pp. 91-95. https://doi.org/10.1109/I2CACIS.2019.8825092

[65] Patil, S.D., Kadwane, S.G. (2017). Application of 
optimization technique in she controlled multilevel inverter. International Conference on Energy, Communication, Data Analytics and Soft Computing (ICECDS-2017), pp. 26-30. https://doi.org/10.1109/ICECDS.2017.8390050

[66] Mohanty, R., Chatterjee, D., Suman, S., Sengupta, G. (2019). PSO based improved topology for MLI considering low THD and low switching loss. 2019 10th International Conference on Computing, Communication and Networking Technologies (ICCCNT), Kanpur, India, pp. 1-5. https://doi.org/10.1109/ICCCNT45670.2019.8944546

[67] Babaei, M., Rastegar, H. (2017). Selective harmonic elimination PWM using ant colony optimization. In 2017 Iranian Conference on Electrical Engineering (ICEE), Tehran, Iran, pp. 1054-1059. IEEE.10.1109/IranianCEE.2017.7985195

[68] Nalcaci, G., Ermis, M. (2018). Selective harmonic elimination for three-phase voltage source inverters using whale optimizer algorithm. 2018 5th International Conference on Electrical and Electronic Engineering (ICEEE), Istanbul, Turkey, pp. 1-6. https://doi.org/10.1109/ICEEE2.2018.8391290

[69] Sahu, J.K., Mishra, S.K., Hariharan, K. (2019). Harmonic analysis of three phase inverter by using particle swarm optimization technique. Second International Conference on Smart Systems and Inventive Technology (ICSSIT 2019), Tirunelveli, India, pp. 1158-1162. https://doi.org/10.1109/ICSSIT46314.2019.8987755

[70] Cai, X., Wu, Z., Li, Q., Wang, S. (2016). An improved phase-shifted carrier pulse width modulation based on the artificial bee colony algorithm for cascaded H-Bridge multilevel inverters. Journal of Power Electronics, 16(2): 512-521. https://doi.org/10.6113/jpe.2016.16.2.512

[71] Manai, L., Dabboussi, M., Armi, F., Besbes, M. (2016). Cascaded multilevel inverter control considering low harmonic content based on comparison study between firefly and Newton Raphson Algorithm. 2016 4th International Conference on Control Engineering \& Information Technology (CEIT), Tunisia, Hammamet, pp. 1-5. https://doi.org/10.1109/CEIT.2016.7929093

[72] Patil, S.D., Kadwane, S.G., Kadu, A. (2020). Hybrid optimization approach applied for harmonic reduction in multilevel inverter. First International Conference on Power, Control and Computing Technologies (ICPC2T), Raipur, India, pp. 79-84. https://doi.org/10.1109/ICPC2T48082.2020.9071509

[73] Rtibi, W., Yaich, M., Hanini, W., M'barki, L., Ayadi, M. (2020). The ant colony optimization algorithm application on the speed control of the electrical vehicle system powered by the five-level NPC inverter. $20201 \mathrm{st}$ International Conference on Innovative Research in Applied Science, Engineering and Technology (IRASET), Meknes, Morocco, pp. 1-6. https://doi.org/10.1109/IRASET48871.2020.9092132

[74] Babaie, M., Sharifzadeh, M., Mehrasa, M., Al-Haddad, K. (2019). Optimized based algorithm first order sliding mode control for grid-connected packed e-cell (PEC) inverter. 2019 IEEE Energy Conversion Congress and Exposition (ECCE), Baltimore, MD, USA, pp. 2269-
2273. https://doi.org/10.1109/ECCE.2019.8913100

[75] Baghaee, H.R., Mirsalim, M., Gharehpetian, G.B., Talebi, H.A., Niknam-Kumle, A. (2017). A hybrid ANFIS/ABC-based online selective harmonic elimination switching pattern for cascaded multi-level inverters of microgrids. IEEE Trans. Ind. Electron, 99: 110. https://doi.org/10.1109/tie.2017.2694403

[76] Kumar, N.V., Chinnaiyan, V.K., Pradish, M., Divekar, M.S. (2016). Selective harmonic elimination: A comparative analysis for seven level inverter. 2016 IEEE Students' Technology Symposium (TechSym), Kharagpur, India, pp. 157-162. https://doi.org/10.1109/TechSym.2016.7872674

[77] Dzung, P.Q., Tien, N.T., Tuyen, N.D., Lee, H.H. (2015). Selective harmonic elimination for cascaded multilevel inverters using grey wolf optimizer algorithm. In 2015 9th International Conference on Power Electronics and ECCE Asia (ICPE-ECCE Asia), Seoul, Korea, pp. 27762781. https://doi.org/10.1109/ICPE.2015.7168164

[78] Ganesan, K., Barathi, K., Chandrasekar, P., Balaji, D. (2015). Selective harmonic elimination of cascaded multilevel inverter using BAT algorithm. Procedia Technology, 21: 651-657. https://doi.org/10.1016/j.protcy.2015.10.078

[79] Adeyemo, I., Fakolujo, O., Adepoju, G. (2015). Ant colony optimisation approach to selective harmonic elimination in multilevel Inverter. IMPACT: International Journal of Research in Engineering \& Technology, 3: 31-42.

[80] Patil, S.D., Kadwane, S.G., Gawande, S.P. (2016). Ant colony optimization applied to selective harmonic elimination in multilevel inverters. 2016 2nd International Conference on Applied and Theoretical Computing and Communication Technology (iCATccT), Bangalore, India, pp. 637-640. https://doi.org/10.1109/ICATCCT.2016.7912078

[81] Mousazadeh Mousavi, S.Y., Zabihi Laharami, M., Niknam Kumle, A., Fathi, S.H. (2018). Application of $\mathrm{ABC}$ algorithm for selective harmonic elimination switching pattern of cascade multilevel inverter with unequal DC sources. International Transactions on Electrical Energy Systems, 28(4): e2522. https://doi.org/10.1002/etep.2522

[82] Sultana, W.R., Sahoo, S.K., Karthikeyan, S.P., Raglend, I.J., Chandrashekar, A., Pradeep, A.S. (2015). Application of Bacterial Foraging Optimization for Elimination of Lower Order Harmonics in Seven Level Inverter. Power Electronics and Renewable Energy Systems, pp. 1173-1181. https://doi.org/10.1007/978-81322-2119-7_114

[83] Sundari, M.G., Rajaram, M., Balaraman, S. (2016). Application of improved firefly algorithm for programmed PWM in multilevel inverter with adjustable DC sources. Applied Soft Computing, 41: 169-179. https://doi.org/10.1016/j.asoc.2015.12.036

[84] Mars, J., Hundt, R. (2009). Scenario based optimization: A framework for statically enabling online optimizations. 2009 International Symposium on Code Generation and Optimization, Seattle, WA, USA, pp. 169-179. https://doi.org/10.1109/CGO.2009.24 